\title{
The Effects of Cultural Background and Knowledge Creation on Self-Employment and Entry Density Rates
}

\author{
Panagiotis E. Petrakis(Correspondence author) and Pantelis C. Kostis \\ Faculty of Economics, National and Kapodistrian University of Athens \\ 5 Stadiou Street, PC 10562, Athens, GREECE \\ Tel:+30-2103689353 E-mail: ppetrak@econ.uoa.gr and pkostis@econ.uoa.gr
}

\begin{abstract}
$\boldsymbol{A}$ bstract: This paper contributes to the interpretation of entrepreneurship based on the effect of knowledge and cultural background. Entrepreneurship is defined as both the self-employment and the entry density rates, comparing the two models. The present paper uses a series of variables to express these effects, which are analyzed with a principal component analysis and a regression analysis. The results confirm that cultural background strongly affects both entrepreneurship rates. Knowledge creation does not affect entrepreneurship rates, as its impact on entrepreneurship is long-lasting (it could reach more or less 10 years) and not a short-term one.

Simultaneously, knowledge impact affects negatively the self-employment rates and positively the entry density rates in the economies. Furthermore, performing a sensitivity analysis on knowledge and cultural background, the conclusions confirm that cultural background has a strong interpretive role in both entrepreneurship rates. Moreover, under the new prevailing conditions the creation of knowledge and the impact of knowledge have a negative effect on self-employment, while the effect of knowledge impact is strengthened in the cases where we increase knowledge and it is weakened where we decrease the knowledge variables.
\end{abstract}

JEL Classifications: D83; L26; Z10

Keywords: Cultural background; Entrepreneurship; Entry density; Knowledge; Self-employment

\section{Introduction}

The purpose of this paper is to identify and quantify the effects of knowledge and culture on the entrepreneurship of societies. The concept of entrepreneurship is approached through two different variables: a) the self-employment rates and b) the entry of new firms in the economy, so that we can explore the differences in the results when we use different variables expressing the concept of entrepreneurship.

Romer (1986) and Lucas (1993) formalized the explicit introduction of knowledge into macro economic growth models. This introduction shifted the focus of policy to knowledge, which became particularly potent in terms of its impact on growth when compared to the traditional factors of physical capital and labour, where no such spillovers and free access by third-party firms was possible (Audretsch, 2007).

At the same time, the definition of entrepreneurial opportunities raises the question of the exact impact of culture on entrepreneurship, as indicated by disciplines such as economics (Schumpeter, 1934), sociology (Weber, 1930) and psychology (McClelland, 1961). Moreover, it involves several issues attributed to the social characteristics that constitute what we understand as "culture".

The contribution of the present paper to the literature lies, in the first place, in that it investigates the simultaneous effect of knowledge and culture on entrepreneurship. Secondly, this 
paper considers two different types of entrepreneurship: self-employment and entry density and it makes a comparison between the two. Thirdly, it investigates the issue of endogeneity between selfemployment, entry density and the knowledge and cultural background. Finally, the paper contributes through a sensitivity analysis which examines the change in the structure of knowledge and the cultural background of societies, as well as the new conditions shaped for the selfemployment and the entry density rates.

The order of the paper is as follows: Section 2 presents the theoretical background and more specifically, the concept of knowledge in general, as well as its effects on the economic behaviour, the concept of knowledge in the Institutional/ Post-Keynesian model and the relationship between cultural background and entrepreneurship. Section 3 presents the data used in the empirical analysis. The following session (Section 4), describes the methodology employed, i.e., the empirical model and measurements, while Section 5 presents the empirical work and the discussion of the results. Finally, Section 6 presents the conclusions.

\section{Entrepreneurship Identification, Knowledge and Cultural Background}

The identification and the exploitation of entrepreneurial opportunities are an important part of the entrepreneurial process. The theory of Entrepreneurship identification tends to conclude in three basic schools of thought for the identification of investment opportunities (Companys and McMullen, 2007).

The Economic School defines an entrepreneurial opportunity as an objective phenomenon that exists in time and space, which may be unknown to some people (Shane, 2003; Shane and Venkataraman, 2000). Better access to information and knowledge, improves the ability of a person to identify entrepreneurial opportunities (Shane, 2003; Shane and Venkataraman, 2000). Kirzner (1973) argues that opportunities exist; but someone has to identify them. According to Mitchell (2001) entrepreneurial cognition is the knowledge structures that people use in order to make assessments, judgments or to make decisions involving opportunity evaluation, venture creation and growth. The Economic School attributes entrepreneurial opportunities to the distribution of information regarding the material opportunities that exist in the society (David and Foray, 2003).

The School of Culture supports that entrepreneurial opportunities are subjective and not objective constructions-phenomena (Sarasvathy, et al., 2003). According to Weick (1979), there are entrepreneurial opportunities to the extent that individuals comprehend their existence. Entrepreneurial opportunities do not exist in an objective way waiting for someone to discover them. The existence of a specific cultural background forms the basis of a sustainable competitive advantage (Rindova, et al., 2003). As far as entrepreneurs are concerned, they define business opportunities through social interactions. The differences in the distribution of knowledge are the primary source of business opportunities. However, it argues that the differences in the cognitive level, that influence the capability to perceive entrepreneurial opportunities, are due to cultural reasons and not to the amount of factual information or past experiences (Shane, 2000). Additionally, entrepreneurial opportunities can be actively created by the entrepreneur himself (Sarasvathy, et al., 2003).

Finally, the Sociopolitical School supports the important role administrative mechanisms play in the definition of entrepreneurial opportunities (Granovetter, 1985). It stresses out the objective properties of entrepreneurial opportunities. Furthermore, it emphasizes on the political procedures that are being exercised so as to bear to seize entrepreneurial opportunities (Fligstein, 1996). It considers that entrepreneurial opportunities exist and evolve into complex networks of social relations, which are shaping the economic activity. The placement of actors in a concrete network 
determines the mass of critical resources and information that the actor may dispose in order to exploit the opportunities (Burt, 1992). The mechanisms of management are, in fact, the rules of the game that affect both the behavior of individuals (DiMaggio and Powell, 1983) and the conditions imposed by the external environment.

Regardless of the methodology with which the issue of the recognition of entrepreneurial opportunities is approached, two key factors seem to play a role first in the identification of entrepreneurial opportunities and then in their activation as entrepreneurship events: Knowledge and the Cultural Background of societies.

\subsection{Knowledge and Entrepreneurship}

Knowledge is now considered to be a valuable commodity, and concepts such as knowledge sharing and lifelong learning have become increasingly prevalent in business practices. Martins (2011) states that knowledge is more than information, since it involves understanding obtained through learning and experience. De Witte and van den Brink (2011) suggest that even without major increases in (public) funding, improvements in educational outcomes and thus knowledge improve economic performance.

According to Karlsson, et al. (2004), knowledge can be defined as scientific knowledge, technological knowledge and entrepreneurial knowledge. The first two definitions of knowledge are more associated with incumbents, such as firms or universities. Entrepreneurial knowledge, comprises specific knowledge tied to the market and the functioning of an economy and is connected to what is required in order to introduce an innovation (Schumpeter, 1911). Moreover, the ability to recognize and capitalize entrepreneurial opportunities can be considered as part of the cognitive background of a person.

The expected economic value of knowledge or of a new idea varies significantly among economic actors. The different level of education and the differences in the background and the experience of economic actors create different conditions associated with knowledge, the high degree of uncertainty, information asymmetries and the cost of transactions, and they lead to different decisions (Audrestch, 2007). In line with the Cultural School, the above differences may lead to discrepancies regarding the identification, the evaluation and the decision making of realizing entrepreneurial opportunities among economic actors, due to the different perception about the expected value of a new project.

Between knowledge with a potential commercial value and knowledge that is actually commercialized there is a knowledge filter (Audretsch, et al., 2006). Thus, the knowledge filter activates the knowledge and it transforms it into business activity. In a sense the present paper detects the role and the operation of the knowledge filters.

About the concept of the management of knowledge, it is the subject of systematic research to discover the roots of business development (Nonaka, 1994; Randeree, 2006). If businesses use knowledge properly, they gain a competitive advantage in becoming more sustainable, competitive and innovative. Businesses have an integrated wealth of knowledge, which is established through their working practices, management systems and human resources (Petrakis and Kostis, 2012).

Organisational knowledge is not easily imitated by a firm's competition, which results in a sustainable competitive advantage and a strategic asset for businesses (Bollinger and Smith, 2001). The challenge for businesses is to be able to capture that knowledge and to leverage it through their operations. The investments in new knowledge by the firms and the organizations not only do they create an opportunity for a comparative advantage to the firms themselves, but they also form the conditions for knowledge to spill over, for other third-party firms as well (Griliches, 1992). 


\subsection{Cultural Background and Entrepreneurship}

McClelland (1961) attempted to relate societal values with entrepreneurial variables and economic dynamism in general. Furthermore, he attempted to quantify the impact of entrepreneurship culture in economic development without using an economic model. Lynn (1991), also without using a model, concluded that countries moving towards competing values are associated with higher levels of economic development. Grief (1994) highlights the fact that different cultural values lead to different societal structures of economic relationships. Furthermore, Bunzel and Kelemen (2011) suggest that while much emphasis has been put upon developing a region's infrastructure, developmental policies and strategies need to reflect the corresponding regional culture.

Cultural and institutional factors may explain cross-national differences in levels of entrepreneurial activity (Wennekers, et al., 2002). Thomas and Meller (2000) found that differences in cultural orientation between countries- affect the personality characteristics commonly associated with motivation for entrepreneurship. Furthermore, studying regional differences of entrepreneurial culture in Sweden using cultural values and belief data, Davidsson and Wiklund (1997) concluded that there is a weak relationship between entrepreneurial values and the formation of new regional firms.

Shane (1993) found a strong influence of Hofstede's (1980) cultural value of uncertainty avoidance on the levels of innovativeness of societies. Morris et al. (1994) focused on the variable of individualism, which is related both to the desire of people to violate norms and to incentives for achievement (Hofstede 1980), which are characteristics associated with entrepreneurship. Wildeman, et al. (1999) examined the effects of Hofstede's (1980) cultural variables of power distance and uncertainty avoidance on entrepreneurship and showed that they positively influence levels of self-employment.

In general, we may approach the relationship between cultural values and entrepreneurial activity from two different perspectives. These are the supply or "pull" perspectives and the demand or "push" perspectives. On the supply side, we have the "legitimation of entrepreneurship" and the "aggregate psychological traits", and on the demand side, we have the "dissatisfaction perspective" for business start-ups and entrepreneurship in general (Thurik, et al., 2008; Wennekers, et al., 2008). The predicted relationship between the "push" and "pull" perspectives is the opposite (Wennekers, et al., 2008).

The "legitimation of entrepreneurship", focuses on the impact of the norms and institutions on society at large (Etzioni, 1987). The cultural determinants of entrepreneurship may also include "aggregate psychological traits", as more entrepreneurial values in a society can lead to an increase in the number of people displaying entrepreneurial behaviour (Davidsson, 2004). An other explanation for entrepreneurship is what is called the "dissatisfaction perspective", which, at the macro level, assumes that differences in values between the population as a whole and potential entrepreneurs form the basis for variation in entrepreneurship. Baum et al. (1993) concluded that countries with a high degree of uncertainty are associated with higher rates of self-employment, explaining that the cultural determinants of entrepreneurship as the "push explanation for entrepreneurship". On the level of business ownership, Wennekers, et al. (2008) identified a strong, positive effect of uncertainty avoidance on business ownership, concluding that high levels of uncertainty avoidance push people into entrepreneurship through self-employment.

\section{The Data}

The data for the self-employment and the entry density variables, concern the mean performance of each country for the time period of 2008-2009. For the variables expressing cultural background, the reference period is the 1995-1997. There has not been a more recent organised 
effort to measure the cultural background in so many countries. Moreover, the social stereotypes forming the cultural background may be characterised as long lasting, as the forces that have shaped the construction of the stereotypes are considered exogenous (e.g., climate and environment) (Schwartz, 2009). Thus, cultural values present stability through time. In general, cultural stereotypes present a great resistance towards change and to their own redefinition (Johnston, 1996). Therefore, for the period analysed, the variables related to the cultural background may be regarded as constants. Lastly, the data for the variables knowledge creation and knowledge impact concern the year 2009.

Our limited degrees of freedom (due to the small sample we have available because of our limited number of observations on Self-employment and Entry Density rates) do not permit us to deepen our analysis in this respect. These variables are precisely defined in Table 1.

Table 1. Definition of variables and data sources

\begin{tabular}{|c|c|c|c|c|}
\hline & Variables & Definition & $\begin{array}{l}\text { Reference } \\
\text { period }\end{array}$ & Data Source \\
\hline & Self-Employment & $\begin{array}{l}\text { Self employed workers are those workers who, working on their } \\
\text { own account or with one or a few partners or in cooperative, } \\
\text { hold the type of jobs defined as a "self-employment jobs." }\end{array}$ & $2008-2009$ & $\begin{array}{l}\text { International Labour } \\
\text { Organization }\end{array}$ \\
\hline & Entry Density & $\begin{array}{l}\text { The number of newly registered limited liability companies } \\
\text { per } 1,000 \text { working age }(15-64) \text { people. }\end{array}$ & $2008-2009$ & $\begin{array}{l}\text { The World Bank Entrepreneurship } \\
\text { Snapshots } 2010 \\
\text { "Measuring the Impact of the } \\
\text { Financial Crisis on New Business } \\
\text { Registration" }\end{array}$ \\
\hline \multirow{9}{*}{ 罗 } & $\begin{array}{c}\text { Performance } \\
\text { Orientation }\end{array}$ & $\begin{array}{l}\text { The degree to which a society encourages and rewards its } \\
\text { members for performance improvement and excellence. }\end{array}$ & \multirow{9}{*}{ 1995-1997 } & \multirow{9}{*}{ House J. R., et al. (2004) } \\
\hline & $\begin{array}{l}\text { Future } \\
\text { Orientation }\end{array}$ & $\begin{array}{l}\text { The extent to which individuals engage in future-oriented } \\
\text { behaviours, such as delaying gratification, planning and } \\
\text { investing in the future. }\end{array}$ & & \\
\hline & $\begin{array}{c}\text { Gender } \\
\text { Egalitarianism } \\
\end{array}$ & The degree to which a society minimises gender inequality. & & \\
\hline & Assertiveness & $\begin{array}{l}\text { The degree to which individuals are assertive, } \\
\text { confrontational and aggressive in their relationships with } \\
\text { others. }\end{array}$ & & \\
\hline & $\begin{array}{l}\text { Institutional } \\
\text { Collectivism }\end{array}$ & $\begin{array}{l}\text { The degree to which organisational and societal practices } \\
\text { encourage and reward collective distribution of resources } \\
\text { and collective action. }\end{array}$ & & \\
\hline & $\begin{array}{c}\text { In-group } \\
\text { Collectivism } \\
\end{array}$ & $\begin{array}{l}\text { The degree to which individuals express pride, loyalty and } \\
\text { cohesiveness in their organisations or families. }\end{array}$ & & \\
\hline & Power Distance & $\begin{array}{l}\text { The degree to which members of a society expect power to } \\
\text { be distributed equally. }\end{array}$ & & \\
\hline & $\begin{array}{l}\text { Human } \\
\text { Orientation }\end{array}$ & $\begin{array}{l}\text { The degree to which a society encourages and rewards } \\
\text { individuals for being fair, altruistic, generous, caring and } \\
\text { kind to others. }\end{array}$ & & \\
\hline & $\begin{array}{l}\text { Uncertainty } \\
\text { Avoidance }\end{array}$ & $\begin{array}{l}\text { The extent to which members of an organization or society } \\
\text { strive to avoid uncertainty by reliance on social norms, rituals, } \\
\text { and bureaucratic practices to alleviate the unpredictability of } \\
\text { future events. }\end{array}$ & & \\
\hline 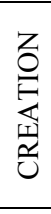 & $\begin{array}{l}\text { Knowledge } \\
\text { Creation }\end{array}$ & $\begin{array}{l}\text { It includes four indicators that are the result of inventive and } \\
\text { innovation activities: patent applications filed by residents both } \\
\text { at the national patent office and at the international level through } \\
\text { the Patent Cooperation Treaty; utility model applications filed } \\
\text { by residents at the national office; and scientific and technical } \\
\text { published articles in peer-reviewed journals. }\end{array}$ & \multirow[t]{2}{*}{2009} & \multirow{2}{*}{$\begin{array}{l}\text { Global Innovation Index } 2011 \text {, } \\
\text { INSEAD }\end{array}$} \\
\hline 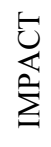 & $\begin{array}{l}\text { Knowledge } \\
\text { Impact }\end{array}$ & $\begin{array}{l}\text { It includes three statistics representing the impact of } \\
\text { innovation activities at the micro and macroeconomic level: } \\
\text { increases in labour productivity, the entry of new firms, and } \\
\text { spending on software. }\end{array}$ & & \\
\hline
\end{tabular}


Notes: The 45 countries in the sample represent 78.86\% of global GDP, 2009 (IMF Database). The countries are Argentina, Australia, Austria, Bolivia, Brazil, Canada, Colombia, Costa Rica, Denmark, Ecuador, Egypt, El Salvador, Finland, France, Georgia, Germany, Greece, Hong Kong, Hungary, Indonesia, Ireland, Italy, Japan, Kazakhstan, Malaysia, Mexico, Morocco, Netherlands, New Zealand, Philippines, Poland, Portugal, Russian Federation, Singapore, Slovenia, South Africa, Korea Rep., Spain, Sweden, Switzerland, Thailand, Turkey, United Kingdom, United States, Venezuela.

\section{The Methodology Employed}

We examine the following two hypotheses.

$$
\begin{aligned}
& \text { Self-Employment }_{i}=\beta_{0}+\beta_{1} * C U L T_{i}+\beta_{2} * \text { CREATION }_{i}+\beta_{3} * I M P A C T_{i}+\varepsilon_{i} \\
& \text { Entry Density }_{i}=\gamma_{0}+\gamma_{1} * C U L T_{i}+\gamma_{2} * C R E A T I O N_{i}+\gamma_{3} * I M P A C T_{i}+\varepsilon_{i}
\end{aligned}
$$

The two hypotheses vary vis-à-vis the dependent variable they use. In the first hypothesis the dependent variable is the Self-Employment rates, while in the second it is the Entry Density rates in the economies. CULT is the Principal Component (PC) that arises from the variables expressing the cultural background, after a Principal Component Analysis (PCA); CREATION refers to the Knowledge Creation and IMPACT refers to the Knowledge Impact.

In order to abstract from the complexity of the cultural background of societies as an explanatory variable, we used the PCA. This methodology allows us to reduce the number of variables representing cultural background, while detecting the structure in the relationships between these variables. Smith (2002) commented that PCA is a way of identifying patterns in data and expressing the data in such a way as to highlight their similarities and differences. More specifically, it is a factor extraction method used to form uncorrelated linear combinations of the observed variables, which is then used to obtain the initial factor solution, when a correlation matrix is singular. The first principal component (PC) has a maximum variance. Successive components explain progressively smaller portions of the variance and are all uncorrelated with each other.

We apply PCA to the group of variables expressing cultural background. The effect of the PCs on Self-Employment and Entry Density is examined through a linear regression using the ordinary least squares method (OLS), as in the two hypotheses presented above. In our linear regression, we used the principal components with the greatest variances (initial eigenvalues $>0.97$ ).

To check for endogeneity between the variables used, we use a version of the Hausman test (Hausman, 1978) proposed by Davidson and MacKinnon (1989, 1993), which employs a test statistic for exogeneity by running an auxiliary regression. The null hypothesis states that the model yields consistent estimates and the reported values of p-value state the probability that the test statistic is zero, which would imply the acceptance of the null hypothesis. In this test, we use a set of instrumental variables that are correlated with the "suspect" variable but not with the error term of the regression that applies Self-Employment or Entry Density as a dependent variable. Only if endogeneity is not present will the OLS estimates be consistent and unbiased. In addition, the partial instrumental variables $\mathrm{R}^{2}$ are reported to describe how much of the squared residuals can be explained by the instrumental variables. The partial $\mathrm{p}$-value, which is the probability that the Fvalue for each instrumental variable is zero, is also reported. Both tests describe how good (strong) the instrumental variables are in explaining Self-Employment and Entry Density rates.

If we identify endogeneity between the variables used, the structural system of the equations (one equation for each of the endogenous variables as a dependent variable) will be estimated with the two-stages least squares (2SLS). In this method, as exogenous variables, we will use the variables that seem to have no direct causal path to the endogenous variables, whose disturbance term is correlated with that of the problematic causal variable. This method covers models that 
violate the ordinary least squares (OLS) regression's assumption of recursivity (when the model involves feedback loops), specifically models in which the disturbance term of the dependent variable correlates with the cause(s) of the independent variable(s). In the first stage, new dependent or endogenous variables are created to substitute for the original variables by using selected instrumental variables, which replace the problematic causal variables so as not to violate the OLS regression's recursivity assumption. In the second stage, the regression is computed in OLS fashion, but with the newly created variables.

Furthermore, a sensitivity analysis on this basic scenario is included. The scope of this experiment is to evaluate the effect of culture and knowledge on Self-Employment and Entry Density rates under changing circumstances in the societies. For each hypothesis, we create eight different possible combinations of cultural background and knowledge in societies, through increasing or decreasing the values of the variables expressing it, where the values of the variables of each group are improved, weakened or remain unchanged. To get improved/weakened all variables are increased/ reduced by $30 \%$ for the countries scoring below/over the average score of the sample. For the variables expressing cultural background, and more specifically for the variables power distance and uncertainty avoidance which are adverse scored, in order to get improved, their values are reduced by $30 \%$ for the countries scoring over the average score of the sample (and viceversa). Figure 1 represents the plan of the sensitivity analysis.

After the sensitivity analysis, we run a new PCA with the PCs for cultural background variables shaped by new forces for each case. Subsequently, for each case of the sensitivity analysis, we evaluate the effect of the new PCs in combination with the new variables for knowledge, first on self-employment and then on entry density rates.

\begin{tabular}{|c|c|c|c|}
\hline $\begin{array}{c}\text { (Case 1) } \\
-30 \% \text { on Culture } \\
-30 \% \text { on Knowledge }\end{array}$ & \multicolumn{2}{|c|}{$\begin{array}{c}\text { (Case 2) } \\
0 \% \text { on Culture } \\
-\mathbf{3 0} \% \text { on Knowledge }\end{array}$} & $\begin{array}{c}\text { (Case } 3 \text { ) } \\
+30 \% \text { on Culture } \\
-\mathbf{3 0} \% \text { on Knowledge }\end{array}$ \\
\hline $\begin{array}{c}\text { (Case } 4 \text { ) } \\
-30 \% \text { on Culture } \\
0 \% \text { on Knowledge }\end{array}$ & \multicolumn{2}{|c|}{\begin{tabular}{c|c|} 
Basic & $\begin{array}{c}\text { Self } \\
\text { Employment }\end{array}$ \\
\cline { 2 - 3 } Model & $\begin{array}{c}\text { Entry } \\
\text { Density }\end{array}$ \\
\end{tabular}} & $\begin{array}{c}\text { (Case } 5) \\
+30 \% \text { on Culture } \\
0 \% \text { on Knowledge }\end{array}$ \\
\hline $\begin{array}{c}\text { (Case } 6 \text { ) } \\
-\mathbf{3 0} \% \text { on Culture } \\
+\mathbf{3 0} \% \text { on Knowledge }\end{array}$ & \multicolumn{2}{|c|}{$\begin{array}{c}0 \% \text { on Culture } \\
+30 \% \text { on Knowledge }\end{array}$} & $\begin{array}{c}\text { (Case } \mathbf{8}) \\
+\mathbf{3 0} \% \text { on Culture } \\
\mathbf{+ 3 0} \% \text { on Knowledge }\end{array}$ \\
\hline
\end{tabular}

Figure 1. The sensitivity analysis

In order to reach these goals (and apart from the description of the new findings), a structural change check is performed relating the alternative circumstances to the basic scenario. In effect, for each variable out of the sixteen cases in total of the sensitivity analysis (eight cases for each dependent variable), we construct two groups of 45 observations. These two groups make a new variable for each of the variables used in the two hypotheses. The first (group 1) concerns the variable's prices in the hypothesis, and the second (group 2) concerns the variable's prices for each case of the sensitivity analysis. The estimates concerning the statistical importance of new factors 
that are created lead us to some conclusions regarding the new configuration and conditions of SelfEmployment and Entry Density rates.

\section{Empirical Work and Discussion of the Results}

In terms of cultural background, four PCs are determined (CULT $1, \mathrm{CULT}_{2}, \mathrm{CULT}_{3}$ and $\mathrm{CULT}_{4}$ in Table 2) that explain $32.88 \%, 25.02 \%, 13.30 \%$ and $10.77 \%$ of the total variance and present initial eigenvalues $2.96,2.25,1.19$ and 0.97 respectively. CULT $_{1}$ is determined by the positive effects of performance orientation, future orientation, institutional collectivism, in-group collectivism and uncertainty avoidance, and the negative effects of human orientation. CULT $_{2}$ is positively shaped by performance orientation, gender egalitarianism, institutional collectivism and human orientation, whereas assertiveness, power distance and uncertainty avoidance have a negative effect. Furthermore, the positive effect of performance orientation, gender egalitarianism, assertiveness, in-group collectivism and power distance and the negative effects of human orientation determine CULT3. Lastly, CULT4 is determined by the positive effects of assertiveness and human orientation.

Table 2 presents the contents of the PCs, i.e., the variables that affect the PC configuration and which have partial correlation values that are greater than 0.3 , in terms of absolute values. Table 3 presents the correlations between the variables used.

Table 2. Principal component matrix

\begin{tabular}{|l|c|c|c|c|}
\hline & CULT $_{1}$ & CULT $_{2}$ & CULT $_{3}$ & CULT $_{4}$ \\
\hline Performance Orientation & 0.57 & 0.53 & 0.39 & \\
\hline Future Orientation & 0.85 & & & \\
\hline Gender Egalitarianism & & 0.78 & 0.40 & \\
\hline Assertiveness & & -0.48 & 0.42 & 0.67 \\
\hline Institutional Collectivism & 0.72 & 0.41 & & \\
\hline In-group Collectivism & 0.71 & & 0.46 & \\
\hline Power Distance & & -0.79 & 0.34 & \\
\hline Human Orientation & -0.38 & 0.40 & -0.43 & 0.61 \\
\hline Uncertainty Avoidance & 0.81 & -0.32 & & \\
\hline
\end{tabular}

Note: There are presented only the values of partial correlations that are greater than 0.3 in terms of absolute values.

Table 3. The two hypotheses

Table 3 presents the empirical results of the estimated regressions. It is presented the effect of cultural background, knowledge impact and knowledge creation on SelfEmployment rates (first column) and on Entry Density rates (second column).

Notes: (1) The parentheses include the t-test statistics for the coefficients of the regressions;

(2) Significance at the $1 \%$, $5 \%$ and $10 \%$ level, is denoted with $* * *, * *$ and $*$, respectively.

\begin{tabular}{|c|c|c|}
\hline Variables & (1)Self-employment & (2)Entry Density \\
\hline $\mathrm{c}$ & $43.88^{* * *}$ & $-6.97^{* * *}$ \\
& $(5.98)$ & $(-4.65)$ \\
\hline \multirow{2}{*}{$\mathrm{CULT}_{1}$} & $5.70^{* *}$ & $0.98^{*}$ \\
& $(2.28)$ & $(1.85)$ \\
\hline \multirow{2}{*}{$\mathrm{CULT}_{2}$} & $-3.46^{*}$ & -0.48 \\
& $(-1.93)$ & $(-1.32)$ \\
\hline \multirow{2}{*}{ CULT $_{3}$} & -1.32 & $0.84^{* *}$ \\
& $(-0.68)$ & $(2.19)$ \\
\hline \multirow{2}{*}{ CULT $_{4}$} & 0.96 & -0.30 \\
& $(0.54)$ & $(-0.83)$ \\
\hline \multirow{2}{*}{ Knowledge creation } & -0.13 & 0.01 \\
& $(-1.50)$ & $(0.64)$ \\
\hline \multirow{2}{*}{ Knowledge impact } & $-0.33^{*}$ & $0.32^{* * *}$ \\
& $(-1.69)$ & $(8.00)$ \\
\hline Adjusted ${ }^{2}$ & 0.442 & 0.710 \\
F-statistic & $6.81^{* * *}$ & $17.76^{* *}$ \\
\hline
\end{tabular}


From the estimation of the first hypothesis (column 1, Table 3), it arises that an increase of $\mathrm{CULT}_{1}$ would positively affect the Self-Employment rates in the economies, as it presents a positive and statistically significant estimate. On the contrary, an increase of $\mathrm{CULT}_{2}$ or Knowledge Impact would negatively affect the Self Employment rates. The $\mathrm{R}^{2}$ of the regression amounts to $44.2 \%$, while according to the F-statistic, the regression is statistically strong. From the second hypothesis (column 2, Table 3), it shows that an increase of $\mathrm{CULT}_{1}, \mathrm{CULT}_{2}$ or Knowledge impact would positively affect the Self-Employment rates in the economies, as they present positive and statistically significant estimates. The $\mathrm{R}^{2}$ of the regression amounts to $71 \%$, while according to the F-statistic, the regression is statistically strong.

Knowledge Creation does seem to affect neither the variable Self-Employment rates nor the variable Entry Density rates. So, it appears that the effect of Knowledge Creation in entrepreneurship is not a short-term one, but instead it affects a much longer time horizon that may reach approximately 10 years. Quite the reverse, what affects both dependent variables is the direct impact of knowledge as expressed by the Knowledge Impact. Finally, the cultural background of societies seems to affect Self-Employment as well as Entry Density.

Table 4. Correlation matrix

\begin{tabular}{|c|c|c|}
\hline Variable & Self-Employment & Entry density \\
\hline CULT $_{1}$ & $0.60^{* *}$ & -0.23 \\
\hline CULT $_{2}$ & -0.23 & -0.17 \\
\hline CULT $_{3}$ & -0.19 & $0.43^{* *}$ \\
\hline CULT $_{4}$ & 0.06 & -0.16 \\
\hline Knowledge Creation $^{*}$ & $-0.52^{* *}$ & 0.13 \\
\hline Knowledge Impact & $-0.48^{* *}$ & $0.81^{* *}$ \\
\hline
\end{tabular}

\section{Notes:}

(1) Significance at the $5 \%$ level is denoted with $* *$;

(2) The correlations between the PCs expressing cultural background are not reported due to the fact that there is no correlation between them at all (correlation is zero).

Observing the correlation matrix (Table 4), one may think that Self-Employment may be endogenously determined by $\mathrm{CULT}_{1}$, Knowledge Creation or Knowledge Impact, while Entry Density may be endogenously determined by $\mathrm{CULT}_{3}$ or Knowledge Impact. Because of the concern of the existence of endogeneity, we use a version of the Davidson and MacKinnon $(1989,1993)$ test described above, for these variables. To test the hypothesis, we use an instrumental variable that correlates with the suspect variable but not with the error term of the Self-Employment or the Entry Density equation. We need to determine whether the instrumental variables are weak or are not as robust as the exogeneity test. Choosing the appropriate instrument is a crucial step. We check for the instruments using the correlation matrix, the partial $\mathrm{R}^{2}$ and the partial F-statistic. All the variables used as instruments are assessed as strong instrumental variables and can be regarded as exogenous with respect to Self-Employment or Entry Density. They present strong correlation with each independent variable but not with Self-Employment or Entry Density and represent a sufficient enough partial $\mathrm{R}^{2}$ and a partial F-statistic bigger that 10 when regressed on each independent variable but not when regressed on Self-Employment or Entry Density. The results of the exogeneity tests do not suggest that there is endogeneity, as the first stage residuals are not statistically different from zero. Consequently, the estimates we draw from hypotheses 1 and 2 are consistent and unbiased.

Next, we cause a shock in the economies by increasing or decreasing by $30 \%$ or maintaining constant the values of the variables expressing cultural background and knowledge (all possible combinations). For the "new" modified variables of cultural background, we run a new PCA. After the PCA, we create the new variables $\mathrm{CULT}_{1}{ }^{\prime}, \mathrm{CULT}_{2}{ }^{\prime}, \mathrm{CULT}_{3}$ ' and $\mathrm{CULT}_{4}$ ' for each case of Fig.1. Table 5 shows the PCA results after the decrease or the increase of the variables that represent the cultural background. At the same time we also modify the variables Knowledge Creation and Knowledge Impact as Knowl Creation' and Knowl Impact'. 
Table 5. The PCA after the sensitivity analysis

\begin{tabular}{|l|c|c|c|c|c|c|c|c|}
\hline & \multicolumn{3}{|c|}{$\mathbf{3 0 \%}$ on Cultural Background } & \multicolumn{3}{|c|}{$+\mathbf{3 0 \%}$ on Cultural Background } \\
\hline & CULT $_{1}{ }^{\prime}$ & CULT $_{2}$ & CULT $_{3}{ }^{\prime}$ & CULT $_{4}{ }^{\prime}$ & CULT $_{1}{ }^{\prime}$ & CULT $_{2}{ }^{2}$ & CULT $_{3}{ }^{\prime}$ & CULT $_{4}{ }^{\prime}$ \\
\hline Performance Orientation & 0.312 & 0.621 & 0.371 & - & - & 0.793 & - & - \\
\hline Future Orientation & 0.371 & - & -0.558 & 0.567 & 0.847 & - & - & - \\
\hline Gender Egalitarianism & 0.513 & - & 0.572 & - & -0.558 & 0.680 & - & - \\
\hline Assertiveness & 0.596 & -0.480 & - & - & - & - & - & 0.931 \\
\hline Institutional Collectivism & -0.639 & - & - & -0.362 & -0.589 & - & 0.352 & - \\
\hline In-group Collectivism & - & 0.716 & - & & 0.412 & 0.621 & 0.384 & - \\
\hline Power Distance & -0.583 & - & - & 0.586 & - & -0.662 & 0.405 & - \\
\hline Human Orientation & - & -0.503 & 0.501 & 0.399 & -0.444 & - & -0.695 & - \\
\hline Uncertainty Avoidance & 0.520 & - & -0.494 & -0.368 & 0.866 & - & - & - \\
\hline
\end{tabular}

Notes: (1) There are presented only the values of partial correlations that are greater than 0.3 ;

(2) The case of $-30 \%$ on Cultural Background is applied on Cases 1, 4 and 6, while that of $+30 \%$ on Cultural Background is applied on Cases 3,5 and 8. In the Cases 2 and 7, where only Knowledge is modified, the powers that shape the cultural background PCs are those in Table 2.

In order to check for the structural change between the two hypotheses and of each case of the sensitivity analysis, we create the variables $\mathrm{CULT}_{1}{ }^{\prime \prime}, \mathrm{CULT}_{2}{ }^{\prime \prime}, \mathrm{CULT}_{3}{ }^{\prime \prime}, \mathrm{CULT}_{4}{ }^{\prime \prime}$, Knowl Creation" and Knowl Impact" (i.e., the difference of the basic scenario from the case of the sensitivity analysis), which arise as values of CULT $1, \mathrm{CULT}_{2}, \mathrm{CULT}_{3}, \mathrm{CULT}_{4}, \mathrm{Knowl}$ Creation and Knowl Impact for group 1 and $\mathrm{CULT}_{1}{ }^{\prime}, \mathrm{CULT}_{2}{ }^{\prime}, \mathrm{CULT}_{3}{ }^{\prime}, \mathrm{CULT}_{4}{ }^{\prime}$, Knowl Creation' and Knowl Impact' for group 2, respectively. The dependent variables Self-Employment and Entry Density are now called Self-Employment" and Entry Density"', and their values for group 1 are repeated for group 2. Subsequently, a dummy variable is created whose value is 0 for group 1 and 1 for group 2 . Following, we create variables dum x $\mathrm{CULT}_{1}{ }^{\prime \prime}$, dum $\mathrm{x} \mathrm{CULT}_{2}{ }^{\prime \prime}$, dum $\mathrm{x} \mathrm{CULT}_{3}{ }^{\prime \prime}$, dum $\mathrm{x} \mathrm{CULT}_{4}{ }^{\prime \prime}$, dum x Knowl Creation" and dum x Knowl Impact" which are the product of the created dummy variable and the variables $\mathrm{CULT}_{1}{ }^{\prime \prime}, \mathrm{CULT}_{2}{ }^{\prime \prime}, \mathrm{CULT}_{3}{ }^{\prime \prime}, \mathrm{CULT}_{4}{ }^{\prime \prime}$, Knowl Creation" and Knowl Impact" respectively.

The shock in the economies produced some statistically significant structural differences. In Table 6 are presented all the regressions of the cases of the sensitivity analysis as well as the structural changes for the eight different cases of figure 1, when Self-Employment is the dependent variable and in Table 7, the same procedure is presented when the dependent variable is the Entry Density rates.

The results of Table 6, regarding the sensitivity analysis and the test for statistically significant structural changes with dependent variable the Self-Employment (hypothesis 1) reveal that there is a significant statistically structural change in all cases where we reduce the cultural background by $30 \%$, when at the same time we reduce by $30 \%$ or maintain or increase by $30 \%$ the variables expressing the Knowledge of societies (Cases 1, 4 and 6 respectively). In other words, a decrease in the values of the variables that reflect the cultural background has a direct impact on SelfEmployment, whichever change may occur in Knowledge. After the sensitivity analysis, the impact of $\mathrm{CULT}_{1}{ }^{\prime}$ is transformed from positive to negative in Case 1, whilst it disappears in Cases 4 and 6. Likewise, the impact of CULT ${ }_{2}^{\prime}$ disappears in all three Cases. Simultaneously, new PCs appear as statistically important: $\mathrm{CULT}_{3}{ }^{\prime}$ in Cases 4 and 6 (positive effect) and $\mathrm{CULT}_{4}{ }^{\prime}$ in Case 1 (negative effect). As far as Knowledge is concerned, under the new circumstances, Knowledge Creation affects in a negative and statistically significant way Self-Employment in all 3 cases. At the same time, the negative effect of the variable Knowledge Impact is strengthened (except for Case 6). 
ISSNs: 1923-7529; 1923-8401 @ 2013 Academic Research Centre of Canada

Table 6. Depended Variable: Self-Employment

\begin{tabular}{|c|c|c|c|c|c|c|c|c|c|c|c|c|c|c|c|c|}
\hline & \multicolumn{2}{|c|}{ Case 1} & \multicolumn{2}{|c|}{ Case 2} & \multicolumn{2}{|c|}{ Case 3} & \multicolumn{2}{|c|}{ Case 4} & \multicolumn{2}{|c|}{ Case 5} & \multicolumn{2}{|c|}{ Case 6} & \multicolumn{2}{|c|}{ Case 7} & \multicolumn{2}{|c|}{ Case 8} \\
\hline & S.A. & S.C. & S.A. & S.C. & S.A. & S.C. & S.A. & S.C. & S.A. & S.C. & S.A. & S.C. & S.A. & S.C. & S.A. & S.C. \\
\hline $\mathrm{c}$ & \begin{tabular}{|c|}
$61.98 * * * *$ \\
$(6.38)$ \\
\end{tabular} & & $\begin{array}{c}49.33^{* * * *} \\
(4.82) \\
\end{array}$ & & \begin{tabular}{|c|}
$58.91 * * *$ \\
$(5.68)$ \\
\end{tabular} & & \begin{tabular}{|c}
$52.01 * * *$ \\
$(7.52)$ \\
\end{tabular} & & \begin{tabular}{|c|}
$48.88 * * *$ \\
$(6.44)$ \\
\end{tabular} & & \begin{tabular}{|c}
$46.36^{* * * *}$ \\
$(8.20)$ \\
\end{tabular} & & \begin{tabular}{|c|}
$40.25 * * *$ \\
$(6.79)$ \\
\end{tabular} & & \begin{tabular}{|c}
$43.68 * * *$ \\
$(7.08)$ \\
\end{tabular} & \\
\hline $\operatorname{CULT}_{1}{ }^{\prime}$ & \begin{tabular}{|l|}
$-0.07 * *$ \\
$(-0.04) ?$ \\
\end{tabular} & & $\begin{array}{l}5.52^{* *} \\
(2.23) \\
\end{array}$ & & $\begin{array}{c}3.97 \\
(1.60) \\
\end{array}$ & & $\begin{array}{c}0.25 \\
(0.13) \\
\end{array}$ & & $\begin{array}{c}4.31 \\
(1.66) \\
\end{array}$ & & $\begin{array}{c}0.12 \\
(0.06) \\
\end{array}$ & & \begin{tabular}{|c|}
$6.11^{* *}$ \\
$(2.46)$ \\
\end{tabular} & & $\begin{array}{l}4.90^{*} \\
(1.88) \\
\end{array}$ & \\
\hline $\mathrm{CULT}_{2}^{\prime}$ & $\begin{array}{c}2.88 \\
(0.18) \\
\end{array}$ & & \begin{tabular}{|l|}
$-3.47^{*}$ \\
$(-1.93)$ \\
\end{tabular} & & \begin{tabular}{|c|}
-2.58 \\
$(-1.41)$ \\
\end{tabular} & & $\begin{array}{c}2.33 \\
(1.12) \\
\end{array}$ & & \begin{tabular}{|c|}
-2.30 \\
$(-1.25)$ \\
\end{tabular} & & $\begin{array}{c}1.86 \\
(0.89) \\
\end{array}$ & & \begin{tabular}{|l|}
$-3.45^{*}$ \\
$(-1.92)$ \\
\end{tabular} & & $\begin{array}{c}-2.07 \\
(-1.12) \\
\end{array}$ & \\
\hline $\mathrm{CULT}_{3}{ }^{\prime}$ & \begin{tabular}{|c|}
3.09 \\
$(0.19)$ \\
\end{tabular} & & \begin{tabular}{|l|}
-1.97 \\
$(-1.09)$ \\
\end{tabular} & & \begin{tabular}{|c|}
-1.62 \\
$(-0.93)$ \\
\end{tabular} & & $\begin{array}{l}3.55^{*} \\
(1.77) \\
\end{array}$ & & \begin{tabular}{|c|}
-0.83 \\
$(-0.45)$ \\
\end{tabular} & & $\begin{array}{l}3.90^{*} \\
(1.92) \\
\end{array}$ & & \begin{tabular}{|c|}
-3.45 \\
$(-1.92)$ \\
\end{tabular} & & $\begin{array}{c}-0.72 \\
(-0.38) \\
\end{array}$ & \\
\hline $\mathrm{CULT}_{4}{ }^{\prime}$ & \begin{tabular}{|l|}
$-3.54 * *$ \\
$(-0.22) ?$
\end{tabular} & & $\begin{array}{c}0.78 \\
(0.44)\end{array}$ & & $\begin{array}{c}3.12 \\
(1.58)\end{array}$ & & $\begin{array}{c}-3.09 \\
(-1.59) \\
\end{array}$ & & $\begin{array}{c}2.72 \\
(1.32) \\
\end{array}$ & & $\begin{array}{c}-3.17 \\
(-1.59) \\
\end{array}$ & & $\begin{array}{c}1.05 \\
(0.59)\end{array}$ & & $\begin{array}{c}2.45 \\
(1.17)\end{array}$ & \\
\hline $\begin{array}{c}\text { Knowl } \\
\text { Creation' } \\
\end{array}$ & \begin{tabular}{|r|}
$-0.41 * * *$ \\
$(-0.44) ?$
\end{tabular} & & $\begin{array}{l}-0.25^{*} \\
(-1.87) \\
\end{array}$ & & \begin{tabular}{|c|}
$-0.42 * * *$ \\
$(-2.89)$ \\
\end{tabular} & & \begin{tabular}{|c|}
$-0.22 * *$ \\
$(-2.50)$ \\
\end{tabular} & & \begin{tabular}{|c|}
$-0.23 * *$ \\
$(-2.38)$ \\
\end{tabular} & & \begin{tabular}{|c|}
$-0.15^{* *}$ \\
$(-2.18)$ \\
\end{tabular} & & \begin{tabular}{|c|}
-0.08 \\
$(-1.27)$ \\
\end{tabular} & & \begin{tabular}{|c|}
$-0.15^{* *}$ \\
$(-2.09)$ \\
\end{tabular} & \\
\hline $\begin{array}{c}\text { Knowl } \\
\text { Impact }\end{array}$ & \begin{tabular}{|c|}
$-0.88 * * *$ \\
$(-0.34)$ \\
\end{tabular} & & $\begin{array}{c}-0.54 \\
(-1.59) \\
\end{array}$ & & \begin{tabular}{|c|}
$-0.76^{* *}$ \\
$(-2.24)$ \\
\end{tabular} & & \begin{tabular}{|c|}
$-0.49 * *$ \\
$(-2.66)$ \\
\end{tabular} & & \begin{tabular}{|l|}
$-0.38^{*}$ \\
$(-1.95)$ \\
\end{tabular} & & \begin{tabular}{|c|}
$-0.30 * *$ \\
$(-2.45)$ \\
\end{tabular} & & \begin{tabular}{|c|}
-0.20 \\
$(-1.61)$ \\
\end{tabular} & & \begin{tabular}{|l|}
$-0.22 *$ \\
$(-1.69)$ \\
\end{tabular} & \\
\hline $\begin{array}{c}\text { dum } x \\
\text { CULT }_{1}{ }^{\prime \prime} \\
\end{array}$ & & $\begin{array}{l}-5.15^{*} \\
(-1.65) \\
\end{array}$ & & \begin{tabular}{|c|}
0.73 \\
$(0.26)$ \\
\end{tabular} & & \begin{tabular}{|c|}
0.76 \\
$(0.27)$ \\
\end{tabular} & & \begin{tabular}{|c|}
-4.94 \\
$(-1.59)$ \\
\end{tabular} & & $\begin{array}{c}-0.30 \\
(-0.11) \\
\end{array}$ & & \begin{tabular}{|l|}
$-5.37^{*}$ \\
$(-1.74)$ \\
\end{tabular} & & $\begin{array}{c}-0.42 \\
(-0.15) \\
\end{array}$ & & $\begin{array}{c}-0.84 \\
(-0.30) \\
\end{array}$ \\
\hline $\begin{array}{c}\operatorname{dum} x \\
\text { CULT }_{2}{ }^{\prime \prime} \\
\end{array}$ & & $\begin{array}{l}5.18^{*} \\
(1.95) \\
\end{array}$ & & $\begin{array}{c}0.01 \\
(0.00) \\
\end{array}$ & & $\begin{array}{c}1.46 \\
(0.58) \\
\end{array}$ & & \begin{tabular}{|l|}
$5.29^{*}$ \\
$(1.98)$ \\
\end{tabular} & & $\begin{array}{c}1.32 \\
(0.52)\end{array}$ & & $\begin{array}{l}5.18^{*} \\
(1.93) \\
\end{array}$ & & $\begin{array}{c}0.03 \\
(0.01) \\
\end{array}$ & & $\begin{array}{c}1.37 \\
(0.54) \\
\end{array}$ \\
\hline $\begin{array}{c}\operatorname{dum} x \\
\text { CULT }_{3}{ }^{\prime \prime} \\
\end{array}$ & & $\begin{array}{c}4.51 \\
(1.61) \\
\end{array}$ & & \begin{tabular}{|c|}
-0.99 \\
$(-0.39)$ \\
\end{tabular} & & \begin{tabular}{|c|}
-0.92 \\
$(-0.36)$ \\
\end{tabular} & & \begin{tabular}{|l|}
$4.78^{*}$ \\
$(1.72)$ \\
\end{tabular} & & $\begin{array}{c}0.08 \\
(0.03) \\
\end{array}$ & & \begin{tabular}{|l|}
$5.16^{*}$ \\
$(1.86)$ \\
\end{tabular} & & $\begin{array}{c}0.49 \\
(0.19) \\
\end{array}$ & & \begin{tabular}{|c}
0.61 \\
$(0.24)$ \\
\end{tabular} \\
\hline $\begin{array}{c}\text { dum } x \\
\text { CULT }_{4}{ }^{\prime \prime} \\
\end{array}$ & & $\begin{array}{l}-5.03^{*} \\
(-1.96) \\
\end{array}$ & & \begin{tabular}{|c|}
-0.09 \\
$(-0.03)$ \\
\end{tabular} & & \begin{tabular}{|c|}
1.57 \\
$(0.60)$ \\
\end{tabular} & & \begin{tabular}{|l|}
$-4.41^{*}$ \\
$(-1.71)$ \\
\end{tabular} & & $\begin{array}{c}1.56 \\
(0.58) \\
\end{array}$ & & \begin{tabular}{|c|}
-4.24 \\
$(-1.62)$ \\
\end{tabular} & & \begin{tabular}{|c|}
0.06 \\
$(0.02)$ \\
\end{tabular} & & \begin{tabular}{|c|}
1.49 \\
$(0.55)$ \\
\end{tabular} \\
\hline $\begin{array}{c}\text { dum } x \\
\text { Knowl } \\
\text { Creation" } \\
\end{array}$ & & $\begin{array}{c}-0.16 \\
(-1.15) \\
\end{array}$ & & $\begin{array}{c}-0.08 \\
(-0.59) \\
\end{array}$ & & $\begin{array}{c}-0.18 \\
(-1.24) \\
\end{array}$ & & $\begin{array}{c}-0.04 \\
(-0.40) \\
\end{array}$ & & $\begin{array}{c}-0.07 \\
(-0.62)\end{array}$ & & $\begin{array}{l}-0.002 \\
(-0.02)\end{array}$ & & $\begin{array}{c}0.03 \\
(0.29)\end{array}$ & & $\begin{array}{c}-0.02 \\
(-0.25)\end{array}$ \\
\hline $\begin{array}{c}\text { dum } x \\
\text { Knowl } \\
\text { Impact" }\end{array}$ & & $\begin{array}{c}-0.04 \\
(-0.25) \\
\end{array}$ & & $\begin{array}{c}-0.06 \\
(-0.39)\end{array}$ & & $\begin{array}{l}-0.005 \\
(-0.03) \\
\end{array}$ & & $\begin{array}{c}0.03 \\
(0.23)\end{array}$ & & $\begin{array}{c}0.06 \\
(0.48) \\
\end{array}$ & & $\begin{array}{c}0.08 \\
(0.73)\end{array}$ & & $\begin{array}{c}0.04 \\
(0.41) \\
\end{array}$ & & $\begin{array}{c}0.10 \\
(0.89)\end{array}$ \\
\hline $\begin{array}{c}\text { Adjusted } \\
\mathrm{R}^{2} \\
\end{array}$ & 0.456 & 0.434 & 0.449 & 0.445 & 0.475 & 0.450 & 0.438 & 0.436 & 0.448 & 0.444 & 0.415 & 0.429 & 0.434 & 0.438 & 0.427 & 0.436 \\
\hline $\begin{array}{c}\mathrm{F}- \\
\text { statistic }\end{array}$ & $7.14^{* * *}$ & 6.69 & $6.97 * * *$ & $6.95 * * *$ & $7.64 * * *$ & $7.06 * * *$ & $6.70^{* * *}$ & $6.73 * * *$ & $6.94 * * *$ & $6.92 * * *$ & $6.19 * * *$ & $6.57 * * *$ & $6.61 * * *$ & $6.77 * * *$ & $6.47^{* * *}$ & $6.73 * * *$ \\
\hline
\end{tabular}

Notes: (1) In each case, there are two independent parts to be tested: Sensitivity Analysis, denoted as S.A., and Structural change, denoted as S.C.

(2)The parentheses include the t-test statistics for the coefficients of the regressions;

(3) Significance at the $1 \%, 5 \%$ and $10 \%$ level, is denoted with ***, $* *$ and *, respectively.

(4) In the structural changes, the variables $\mathrm{CULT}_{1}{ }^{\prime \prime}, \mathrm{CULT}_{2}{ }^{\prime \prime}, \mathrm{CULT}_{3}{ }^{\prime \prime}, \mathrm{CULT}_{4}{ }^{\prime \prime}$, Knowl Creation" and Knowl Impact" are also included but do not display their estimates because they are the same as in the case of the sensitivity analysis, which is presented.

Respectively, the results of Table 7, concerning the sensitivity analysis and the test for statistically significant structural changes with dependent variable the Entry Density (hypothesis 2), show that a statistically significant structural change is observed in three different groups of Cases: a) In Cases where we reduce the variables of Knowledge by $30 \%$, when at the same time we reduce by $30 \%$ or maintain or increase by $30 \%$ the variables that express the cultural background of societies (Cases 1, 2 and 3 respectively). b) In Cases where we increase the variables of Knowledge by $30 \%$, while we reduce by $30 \%$ or maintain or increase by $30 \%$ the variables expressing the cultural background of societies (Cases 6,7 and 8 respectively). c) As in hypothesis 1, in Cases where we reduce the cultural background by $30 \%$, while we decrease by $30 \%$ or maintain or increase by $30 \%$ the variables expressing the Knowledge of societies (Cases 1, 4 and 6 respectively).

In the first group of Cases with dependent variable the Entry Density, the effect of CULT ${ }_{1}^{\prime}$ disappears as far as the cultural background is concerned. Likewise, in Case 1 the effect of CULT ${ }_{3}^{\prime}$ is also lost, whereas in Cases 2 and 3 its positive impact is reinforced. Regarding the variables of 
Knowledge, in all three cases the positive impact of Knowledge Impact on Entry Density is strengthened. In the second group, the positive impact of $\mathrm{CULT}_{1}{ }^{\prime}$ is lost in Cases 6 and 7, while it is intensified in Case 8. On the contrary, the positive impact of $\mathrm{CULT}_{3}{ }^{\prime}$ is reduced in Cases 6 and 7 , while it disappears in Case 8. At the same time, in Case 6 there are two new PC for cultural background with a negative effect on the Entry Density $\left(\mathrm{CULT}_{2}{ }^{\prime}\right.$ and $\left.\mathrm{CULT}_{4}{ }^{\prime}\right)$. Concerning Knowledge, in all three cases the positive effect of Knowledge Impact is decreased. Finally, regarding the third group, in all three Cases the impact of $\mathrm{CULT}_{1}{ }^{\prime}$ disappears. Cases 1 and 6 belong in the other two groups and they have been described above. In Case 4, additionally we observe the entry of $\mathrm{CULT}_{2}{ }^{\prime}$ (with a negative effect on Entry Density), while the impact of $\mathrm{CULT}_{3}{ }^{\prime}$ remains as it is in the basic model. Lastly, an increase of the positive effect of the Knowledge Impact on the Entry Density is noted.

Table 7. Depended Variable: Entry Density

\begin{tabular}{|c|c|c|c|c|c|c|c|c|c|c|c|c|c|c|c|c|}
\hline & \multicolumn{2}{|c|}{ Case 1} & \multicolumn{2}{|c|}{ Case 2} & \multicolumn{2}{|c|}{ Case 3} & \multicolumn{2}{|c|}{ Case 4} & \multicolumn{2}{|c|}{ Case 5} & \multicolumn{2}{|c|}{ Case 6} & \multicolumn{2}{|c|}{ Case 7} & \multicolumn{2}{|c|}{ Case 8} \\
\hline & S.A. & S.C. & S.A. & S.C. & S.A. & S.C. & S.A. & S.C. & S.A. & S.C. & S.A. & S.C. & S.A. & S.C. & S.A. & S.C. \\
\hline $\mathrm{c}$ & $\begin{array}{c}-11.62^{* * *} \\
(-4.11)\end{array}$ & & $\begin{array}{c}-10.35^{\text {**** }} \\
(-4.02) \\
\end{array}$ & & $\begin{array}{c}-11.96^{* * *} \\
(-4.25)\end{array}$ & & $\begin{array}{l}-8.49^{* * * *} \\
(-5.52)\end{array}$ & & $\begin{array}{l}-8.05^{* * * *} \\
(-4.91)\end{array}$ & & $\begin{array}{l}-5.45^{* * *} \\
(-4.37)\end{array}$ & & $\begin{array}{l}-4.18^{* * *} \\
(-3.37)\end{array}$ & & $\begin{array}{l}-4.91^{* * *} \\
(-3.63)\end{array}$ & \\
\hline $\mathrm{CULT}_{1}{ }^{\prime}$ & $\begin{array}{c}0.13 \\
(0.24) \\
\end{array}$ & & $\begin{array}{c}0.70 \\
(1.13)\end{array}$ & & $\begin{array}{c}0.78 \\
(1.22) \\
\end{array}$ & & $\begin{array}{c}-0.24 \\
(-0.57) \\
\end{array}$ & & $\begin{array}{l}1.23 * * \\
(2.24) \\
\end{array}$ & & $\begin{array}{c}-0.21 \\
(-0.48) \\
\end{array}$ & & $\begin{array}{c}0.78 \\
(1.46) \\
\end{array}$ & & $\begin{array}{l}1.09 * \\
(1.92)\end{array}$ & \\
\hline CULT2' & $\begin{array}{c}-0.87 \\
(-1.41) \\
\end{array}$ & & $\begin{array}{c}-0.31 \\
(-0.70) \\
\end{array}$ & & $\begin{array}{c}0.25 \\
(0.51) \\
\end{array}$ & & $\begin{array}{c}-1.01 * * \\
(-2.12) \\
\end{array}$ & & $\begin{array}{c}0.13 \\
(0.33) \\
\end{array}$ & & $\begin{array}{l}-0.83 * \\
(-1.73) \\
\end{array}$ & & $\begin{array}{c}-0.59 \\
(-1.57) \\
\end{array}$ & & $\begin{array}{c}-0.07 \\
(-0.17) \\
\end{array}$ & \\
\hline CULT3' & $\begin{array}{c}0.72 \\
(1.27) \\
\end{array}$ & & \begin{tabular}{|c|}
$1.50 * * *$ \\
$(3.43)$ \\
\end{tabular} & & $\begin{array}{c}1.39 * * * \\
(3.16) \\
\end{array}$ & & $\begin{array}{l}0.84 * \\
(1.90) \\
\end{array}$ & & $\begin{array}{l}0.78 * * \\
(2.05) \\
\end{array}$ & & $\begin{array}{l}0.81 * \\
(1.80) \\
\end{array}$ & & $\begin{array}{l}0.72 * \\
(1.77) \\
\end{array}$ & & $\begin{array}{c}0.64 \\
(1.59) \\
\end{array}$ & \\
\hline CULT4' & $\begin{array}{c}-0.09 \\
(-0.18) \\
\end{array}$ & & $\begin{array}{c}-0.14 \\
(-0.32) \\
\end{array}$ & & $\begin{array}{c}0.73 \\
(-1.38) \\
\end{array}$ & & $\begin{array}{c}-0.69 \\
(-1.65) \\
\end{array}$ & & $\begin{array}{c}-0.45 \\
(-1.01) \\
\end{array}$ & & $\begin{array}{l}-0.76^{*} \\
(-1.76) \\
\end{array}$ & & $\begin{array}{c}-0.39 \\
(-1.08) \\
\end{array}$ & & $\begin{array}{c}-0.26 \\
(-0.57) \\
\end{array}$ & \\
\hline $\begin{array}{c}\text { Knowl } \\
\text { Creation' }\end{array}$ & $\begin{array}{c}0.04 \\
(1.22)\end{array}$ & & $\begin{array}{c}0.03 \\
(0.89) \\
\end{array}$ & & $\begin{array}{c}0.06 \\
(1.56) \\
\end{array}$ & & $\begin{array}{c}0.02 \\
(1.15) \\
\end{array}$ & & $\begin{array}{c}0.02 \\
(1.18) \\
\end{array}$ & & $\begin{array}{c}0.01 \\
(0.81)\end{array}$ & & $\begin{array}{l}0.004 \\
(0.31) \\
\end{array}$ & & $\begin{array}{c}0.01 \\
(0.67) \\
\end{array}$ & \\
\hline $\begin{array}{r}\text { Knowl } \\
\text { Impact' }\end{array}$ & $\begin{array}{c}0.55^{* * *} \\
(5.71)\end{array}$ & & $\begin{array}{c}0.51 * * * \\
(5.85) \\
\end{array}$ & & $\begin{array}{c}0.55^{* * *} \\
(5.94) \\
\end{array}$ & & \begin{tabular}{|c|}
$0.36^{* * *}$ \\
$(8.69)$ \\
\end{tabular} & & \begin{tabular}{|c|}
$0.34 * * *$ \\
$(8.03)$ \\
\end{tabular} & & $\begin{array}{c}0.23 * * * \\
(8.43) \\
\end{array}$ & & $\begin{array}{c}0.20^{* * * *} \\
(7.56) \\
\end{array}$ & & \begin{tabular}{|c|}
$0.22 * * *$ \\
$(7.51)$ \\
\end{tabular} & \\
\hline \begin{tabular}{|c|} 
dum $x$ \\
CULT1" \\
\end{tabular} & & $\begin{array}{c}-1.01 \\
(-1.30) \\
\end{array}$ & & $\begin{array}{c}-0.85 \\
(-1.31) \\
\end{array}$ & & $\begin{array}{c}-1.01 \\
(-1.50) \\
\end{array}$ & & $\begin{array}{c}-1.31 * * \\
(-1.99) \\
\end{array}$ & & $\begin{array}{c}0.02 \\
(0.03) \\
\end{array}$ & & $\begin{array}{c}-1.04 \\
(-1.58) \\
\end{array}$ & & $\begin{array}{c}0.46 \\
(0.78) \\
\end{array}$ & & $\begin{array}{c}0.60 \\
(1.00) \\
\end{array}$ \\
\hline \begin{tabular}{|c|}
$\operatorname{dum} x$ \\
CULT2 $^{\prime \prime}$ \\
\end{tabular} & & $\begin{array}{c}-0.06 \\
(-0.09) \\
\end{array}$ & & $\begin{array}{c}0.13 \\
(0.22) \\
\end{array}$ & & $\begin{array}{c}0.49 \\
(0.83) \\
\end{array}$ & & $\begin{array}{c}-0.42 \\
(-0.73) \\
\end{array}$ & & $\begin{array}{c}0.57 \\
(1.07) \\
\end{array}$ & & $\begin{array}{c}-0.44 \\
(-0.76) \\
\end{array}$ & & $\begin{array}{c}-0.11 \\
(-0.21) \\
\end{array}$ & & $\begin{array}{c}0.48 \\
(0.88) \\
\end{array}$ \\
\hline $\begin{array}{c}\operatorname{dum} x \\
\text { CULT3 }^{\prime \prime} \\
\end{array}$ & & $\begin{array}{c}-0.12 \\
(-0.18) \\
\end{array}$ & & $\begin{array}{c}0.82 \\
(1.45) \\
\end{array}$ & & $\begin{array}{c}0.71 \\
(1.20) \\
\end{array}$ & & $\begin{array}{c}0.01 \\
(0.02) \\
\end{array}$ & & $\begin{array}{c}0.01 \\
(0.03) \\
\end{array}$ & & $\begin{array}{c}-0.06 \\
(-0.11) \\
\end{array}$ & & $\begin{array}{c}-0.42 \\
(-0.80) \\
\end{array}$ & & $\begin{array}{c}-0.37 \\
(-0.70) \\
\end{array}$ \\
\hline \begin{tabular}{|c|} 
dum $x$ \\
CULT4" \\
\end{tabular} & & $\begin{array}{c}0.34 \\
(0.54)\end{array}$ & & $\begin{array}{c}0.08 \\
(0.14)\end{array}$ & & $\begin{array}{c}-0.21 \\
(-0.35) \\
\end{array}$ & & $\begin{array}{c}-0.33 \\
(-0.61) \\
\end{array}$ & & $\begin{array}{c}-0.11 \\
(-0.20) \\
\end{array}$ & & $\begin{array}{c}-0.53 \\
(-0.96) \\
\end{array}$ & & \begin{tabular}{|c|}
-0.06 \\
$(-0.11)$ \\
\end{tabular} & & $\begin{array}{c}-0.03 \\
(-0.06) \\
\end{array}$ \\
\hline \begin{tabular}{|c|} 
dum $x$ \\
Knowl \\
Creation" \\
\end{tabular} & & $\begin{array}{l}0.007 \\
(0.19)\end{array}$ & & $\begin{array}{l}-0.002 \\
(-0.06)\end{array}$ & & $\begin{array}{c}0.01 \\
(0.41)\end{array}$ & & $\begin{array}{l}0.002 \\
(0.09)\end{array}$ & & $\begin{array}{l}0.007 \\
(0.30)\end{array}$ & & $\begin{array}{c}0.01 \\
(0.43) \\
\end{array}$ & & $\begin{array}{r}0.008 \\
(0.41)\end{array}$ & & $\begin{array}{c}0.01 \\
(0.56)\end{array}$ \\
\hline $\begin{array}{c}\text { dum x } \\
\text { Knowl } \\
\text { Impact }^{\prime \prime}\end{array}$ & & $\begin{array}{c}0.08^{* *} \\
(2.28)\end{array}$ & & $\begin{array}{l}0.09 * * \\
(2.57)\end{array}$ & & $\begin{array}{l}0.08^{* *} \\
(2.16)\end{array}$ & & $\begin{array}{l}0.001 \\
(0.04)\end{array}$ & & \begin{tabular}{|l|}
-0.005 \\
$(-0.18)$
\end{tabular} & & \begin{tabular}{|c|}
$-0.06^{* * *}$ \\
$(-2.45)$
\end{tabular} & & \begin{tabular}{|c|}
$-0.06^{* *}$ \\
$(-2.46)$
\end{tabular} & & \begin{tabular}{|c|}
$-0.06 * *$ \\
$(-2.50)$
\end{tabular} \\
\hline \begin{tabular}{|c|} 
Adjusted \\
$\mathrm{R}^{2}$ \\
\end{tabular} & 0.458 & 0.571 & 0.586 & 0.642 & 0.559 & 0.622 & 0.669 & 0.688 & 0.689 & 0.699 & 0.655 & 0.681 & 0.688 & 0.691 & 0.661 & 0.682 \\
\hline $\begin{array}{c}\text { F- } \\
\text { statistic } \\
\end{array}$ & $6.76^{* * *}$ & $10.21 * * *$ & $10.65 * * *$ & $13.39^{* * *}$ & $9.67 * * *$ & $12.37 * * *$ & $14.81 * * *$ & $16.26 * * *$ & $16.10 * * *$ & $17.06 * * *$ & $13.97 * * *$ & $15.74 * * *$ & $16.09 * * *$ & $16.48 * * *$ & $14.35 * * *$ & $15.83 * * *$ \\
\hline
\end{tabular}

Notes:(1) In each case, there are two independent parts to be tested: Sensitivity Analysis, denoted as S.A., and Structural change, denoted as S.C.

(2) The parentheses include the t-test statistics for the coefficients of the regressions;

(3) Significance at the $1 \%, 5 \%$ and $10 \%$ level, is denoted with $* * *, * *$ and *, respectively;

(4) In the structural changes, the variables $\mathrm{CULT}_{1}{ }^{\prime \prime}, \mathrm{CULT}_{2}{ }^{\prime \prime}, \mathrm{CULT}_{3}{ }^{\prime \prime}, \mathrm{CULT}_{4}{ }^{\prime \prime}$, Knowl Creation" and Knowl Impact" are also included but do not display their estimates because they are the same as in the case of the sensitivity analysis, which is presented. 


\section{Conclusions}

This paper attempts to analyse the effects of knowledge and cultural background on entrepreneurship and more specifically on two different types of entrepreneurial measures: the Selfemployment rates and the Entry Density rates. Furthermore, a sensitivity analysis is conducted to examine how the new conditions shaped after the changes in the structure of knowledge and cultural background of the societies affect the self-employment and the entry density rates.

To a great degree, this paper succeeds in highlighting the importance of knowledge and cultural background in entrepreneurship. The interceptive and promoting factors of entrepreneurship are defined with considerable clarity to highlight the importance that the improvement of the special conditions of knowledge and culture would have in the way the Self-employment and the Entry Density rates are formed.

On the one hand, Knowledge Impact affects negatively the Self-Employment rates and positively the Entry Density rates in the economies. On the other hand, Knowledge Creation does not seem to affect the two entrepreneurship variables, as its effect in entrepreneurship is in a longterm (it can reach almost 10 years) and not a short-term one. Simultaneously, the empirical results confirm the effect of cultural background on entrepreneurship, as the cultural background of societies seems to seriously affect both Self-Employment and the Entry Density, depending on the nature of PCs.

Furthermore, sensitivity analysis, through examining all possibilities, has established the effects of special circumstances that improve or worsen societies as far as promoting and interceptive factors are concerned. Reducing the values on the variables that reflect the cultural background has a direct impact on the Self- Employment and the Entry Density rates whichever may be the changes made to Knowledge. Under these new circumstances, the negative impact of the variable Knowledge Impact on the Self-Employment rates is strengthened, while Knowledge Creation affects them in a negative way. Simultaneously, Knowledge Creation seems not to play any role at the Entry Density rates. Moreover, increasing or decreasing the variables representing Knowledge has a direct impact on the Entry Density rates no matter the level of increase or decrease occurring on the cultural background of societies (Cases 1-3, 6-8).

A shortcoming of the present paper is the small sample of countries available, which leads to limited degrees of freedom. This limitation is the result of a lack of extensive data on the variables related to entrepreneurship. Furthermore, the sample was reduced in an effort to find common data among many countries for the variables used. Finally, one may think that the data are not all from the same period of time. However, only cultural background refers to the period 1995-1997, but we consider cultural background as long-lasting in character as cultural values present stability through time.

The present paper may be further extended by providing entrepreneurial policies, analysing the contribution of culture and knowledge in the development of entrepreneurship, or it could include other characteristics of societies and economies that can affect entrepreneurship levels (institutional trust, interpersonal trust, transaction characteristics, economic institutions, etc.).

\section{References}

[1] Audretsch, D.B., Keilbach, M.C., and Lehmann, E.E. (2006), Entrepreneurship and Economic Growth. New York: Oxford University Press.

[2] Audretsch, D.B. (2007), The Entrepreneurial Society, New York: Oxford University Press.

[3] Baum, J.R., Oian, J.D., Erez, M., Schnell, E.R., Smith, K.G., Sims, H.P. et al. (1993), "Nationality and work role interactions: a cultural contrast of Israeli and US entrepreneurs' versus managers' needs". Journal of Business Venturing, 8(6):499-512 
[4] Berry, L.L. (1995), "Relationship Marketing of Services Growing Interest, Emerging Perspectives," Journal of the Academy of Marketing Science, 23:236-245.

[5] Bollinger, A.S., and Smith, R.D. (2001), "Managing Organizational Knowledge as a Strategic Asset", Journal of Knowledge Management, 5(1):8-18.

[6] Bunzel, D., and Kelemen, M. (2011) "Learning from Leipzig? Regional Development and Sociocultural Transition", Review of Economics and Finance, Article ID: 1923-7529-2011-03-52-11.

[7] Burt, R.S. (1992), Structural Holes: The Social Structure of Competition, Harvard University Press.

[8] Companys, Y.E., McMullen, J.S., (2007), "Strategic Entrepreneurs at Work The Nature, Discovery, and Exploitation of Entrepreneurial Opportunities", Small Business Economics, 28:301-322.

[9] David, P.A., and Foray, D., (2003), "Economic fundamentals of the knowledge society". Policy Futures in Education, 1(1):20-49.

[10] Davidson, R., and MacKinnon, J.G. (1989), "Testing for Consistency using Artificial Regressions", Economic Theory, 5:363-384.

[11] Davidson, R., MacKinnon, J.G. (1993), Estimation and Inference in Econometrics, Oxford University Press, New York.

[12] Davidsson, P., and Wiklund, J. (1997), "Values, beliefs and regional variations in new firm formation rates", Journal of Economic Psychology, 18(2,3):179-199.

[13] Davidsson', P. (2004), Researching entrepreneurship, international studies in entrepreneurship. New York: Springer.

[14] De Witte and van den Brink (2011), "The Efficiency of Education in Generating Literacy: A Stochastic Frontier Approach", Review of Economics and Finance, Article ID: 1923-7529-2012-0125-13.

[15] DiMaggio, P.J., and Powell, W.W., (1983), "The iron cage revisited: Institutional isomorphism and collective rationality in organizational fields," American Sociological Review, 48:147-60.

[16] Etzioni, A. (1987), "Entrepreneurship, adaptation and legitimation". Journal of Economic Behaviour and Organization, 8:175-189.

[17] Fligstein, N. (1996), "Markets as Politics: A Political-Cultural Approach to Market Institutions." American Sociological Review, 61:656-73.

[18]Granovetter, M.S. (1985), "Economic action and social structure: the problem of embeddedness". American Journal of Sociology, 91(3):481-510.

[19] Greif, A. (1994), "Cultural Beliefs and the Organization of Society: A Historical and Theoretical Reflection on Collectivist and Individualist Societies", Political Economy, University of Chicago Press 102:912-50.

[20] Griliches, Z. (1992), “The Search for R\&D Spillovers", Scandinavian Journal of Economics, 94 (Supplement): pp.29-47.

[21] Hausman, J.A. (1978), "Specification tests in Econometrics". Econometrica, 46:1251-1271.

[22] Hofstede, G. (1980), Culture's Consequences: International differences in Work-related Values. CA: Sage Publ., Beverly Hills.

[23] House, R.J., Hanges, P.J., Javidan, M., Dorfman, P.W., Gupta, V. (2004), Culture, Leadership and Organisations - The GLOBE study of 62 societies, Thousand Oaks, CA: Sage Publ.

[24] Karlsson, C., Friis C., and Paulsson T., (2004), "Relating Entrepreneurship to Economic Growth", CESIS Electronic Working Paper Series, No. 13.

[25] Kirzner, I.M., (1973), Competition and Entrepreneurship, Chicago, IL: University of Chicago Press.

[26] Lucas, R.E. Jr., (1993), “Making a miracle”, Econometrica, 61:251-272.

[27] Lynn, R. (1991), The secret of the miracle economy: different national attitudes to competitiveness and money, London, The Social Affairs Unit.

[28] Martins, J.M. (2011), Knowledge Transfer to the Subsidiaries: A Case Study of Multinational Enterprise Operating in Overseas, Review of Economics and Finance, Article ID: 1923-7529-201103-74-11. 
[29] McClelland, D.C. (1961), The Achieving Society, Van Nostrand, New Jersey.

[30] Mitchell, R.K., Busenitz, L., Bird, B., Gaglio, C.M., McMullen, J., Morse, E., Smith, B. (2007), "The central question in entrepreneurial cognition research", Entrepreneurship Theory and Practice, 31:1-27.

[31] Morris, M.H., Davis, D..L, Allen, J.W. (1994), "Fostering corporate entrepreneurship: Cross cultural comparisons of the importance of individualism versus collectivism", Journal of International Business Studies, 25(1):65-89.

[32] Nonaka, I. (1994), “A Dynamic Theory of Organizational Knowledge Creation”. Organization. Science, 5(1):14-37.

[33 ]Petrakis, P.E., Kostis P.C. (2012), "The Role of Knowledge and Trust in SMEs", Journal of the Knowledge Economy, DOI 10.1007/s13132-012-0115-6.

[34] Randeree, E. (2006). "Knowledge management: securing the future". Journal of Knowledge Management, 10(4):145-156.

[35] Rindova, V.P., Pollock T.G., and Hayward, M., (2003), Celebrity Firms: The Social Construction of Market Popularity, Seattle, WA: Academy of Management Conference.

[36] Romer, P. (1986), "Increasing Returns and Long-run Growth", Journal of Political Economy, 94 (October): 500-521:1002-37.

[37] Sarasvathy, S.D., Dew N., Velamuri S.R., and Venkatamaran S., (2003), Three Views of Entrepreneurial Opportunity', in Acs Z.J. and Audretsch D.B. (Eds.), Handbook of Entrepreneurship Research, Boston: Kluwer, 141-160.

[38] Schane, S. (1993), "Cultural influences on national rates of innovation", Journal of Business Venturing, 8:59-73.

[39] Schumpeter, J.A., (1911), Die Theorie wirtschaftlicher Entwicklung, Berlin: Duncker \& Humblot, English edition: The Theory of Economic Development (1934). Cambridge: Cambridge University Press.

[40] Schumpeter, J. (1934), The Theory of Economic Development, Cambridge, Massachusetts: Harvard University Press.

[41] Shane, S. (2003), A General Theory of Entrepreneurship - The Individual-Opportunity Nexus. UK: Edward Elgar.

[42] Shane, S., and Venkataraman, S., (2000), "The Promise of Entrepreneurship as a Field of Research", Academy of Management Review, 25(1):218-228.

[43] Smith (2002), "Tutorial on principal components analysis", [On-line] Available at: http://www.cs. otago.ac.nz/cosc453/student_tutorials/principal_components.pdf

[44] Thomas, A.S., and Meller, S.L. (2000), "A case for comparative entrepreneurship: assessing the relevance of culture", Journal of International Business Studies, 31:287-301.

[45] Thurik, A.R., Carree, M.A., van Stel, A.J., Audretsch, D.B. (2008), Does self-employment reduse unemployment? Journal of Business Venturing, 23(6):673-686.

[46] Weber, M. (1930), The Protestant Ethic and the Spirit of Capitalism. Unwin Hyman, London.

[47] Weick, K. (1979), The social psychology of organizing (2nd Ed.). Reading, MA: Addison-Wesley Publishing Company.

[48] Wennekers, A.R.M., Uhlaner, L., Thurik, A.R. (2002), "Etrepreneurship and its conditions: a macro perspective", International Journal of Entrepreneurship Education, (1): 25-64.

[49] Wennekers, S., Thurik, A.R., Van Stel, A.J., Noorderhaven, N.(2008), "Uncertainty avoidance and the rate of business ownership across 21 OECD countries, 1976-2004”, Journal of Evolutionary Economics, 17(2):133-160.

[50] Wildeman, R.E., Hofstede, G., Noorderhaven, N.G., Thurik, A.R., Verhoeven, W.H.J., Wennekers, A.R.M. (1999), Self-employment in 23 OECD countries; the role of cultural and economic factors, Research Report 9811/E, Zoetermeer: EIM Small Business Research and Consultancy. 